\title{
Data Mining Menggunakan Algoritma Apriori untuk Rekomendasi Produk bagi Pelanggan
}

\author{
Data Mining using Apriori Algorithm for Product Recommendation for Customers \\ Ariefana Ria Riszky, Mujiono Sadikin*)

\begin{abstract}
Program Studi Teknik Informatika, Fakultas Ilmu Komputer, Universitas Mercu Buana
\end{abstract} \\ Jl. Raya Meruya Selatan,Kembangan, Jakarta, Indonesia 11650
}

Cara sitasi: A. R. Riszky and M. Sadikin, "Data Mining Menggunakan Algoritma Apriori untuk Rekomendasi Produk bagi Pelanggan," Jurnal Teknologi dan Sistem Komputer, vol. 7 no. 3, pp. 103-108, 2019. doi: 10.14710/jtsiskom.7.3.2019.103-108, [Online].

\begin{abstract}
The implementation of a marketing strategy requires a reference so that promotion can be on target, such as by looking for similarities between product items. This study examines the application of the association rule method and apriori algorithm to the purchase transaction dataset to assist in forming candidate combinations among product items for customer recommended product promotion. The purchase transaction dataset was collected in October and November 2018 with a total data of 1027. In the experiment, the minimum value of support is $85 \%$, and the minimum confidence value is $90 \%$ by processing data using the Weka software 3.9 version. Apriori algorithm can form association rules as a reference in the promotion of company products and decision support in providing product recommendations to customers based on defined minimum support and confidence values.
\end{abstract}

Keywords - apriori algorithm; association rule; product recommendation; data mining; product promotion

Abstrak - Pelaksanaan strategi pemasaran memerlukan acuan agar promosi dapat tepat sasaran, misalnya dengan mencari hubungan kesamaan antar item produk. Penelitian ini mengkaji penerapan metode association rule dan algoritma apriori pada dataset transaksi pembelian untuk membantu membentuk kandidat kombinasi antar item produk dalam promosi rekomendasi produk bagi pelanggan. Dataset transaksi pembelian dikumpulkan pada bulan Oktober dan November 2018 sejumlah 1027 data. Pada eksperimen, ditentukan nilai support minimum 85\% dan nilai confidence minimum $90 \%$ dengan pengolahan data menggunakan software Weka versi 3.9. Algoritma apriori dapat menghasilkan aturan asosiasi sebagai acuan dalam promosi produk dan pendukung keputusan dalam memberikan rekomendasi produk kepada konsumen berdasarkan

\footnotetext{
${ }^{*}$ Penulis korespondensi (Mujiono Sadikin)

Email: mujiono.sadikin@mercubuana.ac.id
}

nilai support dan confidence minimum yang telah ditetapkan.

Kata kunci - algoritma apriori; association rule; rekomendasi produk; data mining; promosi item produk

\section{Pendahuluan}

Meskipun teknologi informasi, khususnya komputasi, telah diadopsi di berbagai bidang, namun masih banyak perusahaan tidak memanfaatkan secara optimum. Perusahaan biasanya memiliki data historis transaksi penjualan dari bulan ke bulan, namun sayangnya hanya digunakan sebagai laporan mingguan dan bulanan saja. Jika semakin lama dibiarkan, maka akan terjadi pertumbuhan data yang menimbulkan kaya data namun miskin informasi. Data yang tidak diolah ini hanya akan mengakibatkan penumpukan data yang tidak bermanfaat [1], [2].

Perusahan seringkali masih menggunakan cara manual dalam strategi pemasaran produknya yang tidak memiliki acuan dan hanya berdasarkan perkiraan. Mekanisme seperti ini mengakibatkan promosi tidak tepat sasaran dan biaya promosi terbuang sia-sia. Untuk mendukung strategi pemasaran, perusahaan perlu memanfaatkan teknologi komputasi. Data transaksi penjualan yang tersimpan dapat memberikan manfaat untuk manajemen perusahaan, misalnya untuk meningkatkan penjualan melalui strategi promosi penjualan produk yang sesuai [3]-[5]. Berbagai kegiatan pemasaran, seperti promosi, dan pemaketan untuk diskon, bisa dilakukan dengan lebih baik dan tepat sasaran dengan memanfaatkan data historis ini. Mayoritas konsumen tertarik dengan program promosi karena dirasakan bisa lebih hemat dalam pengeluaran. Kondisi seperti ini bisa menjadi sarana untuk meningkatkan penjualan, mempertahankan pelanggan, dan memberi kepuasan terhadap pelanggan.

Salah satu informasi penting dari data historis yang bisa dimanfaatkan untuk kepentingan kegiatan pemasaran tersebut adalah frequent pattern (FP). FP ini berisi informasi pola yang sering muncul dari data transaksi. Salah satu teknik untuk menggali informasi FP adalah dengan menggunakan association rule 
sebagai satu metode data mining yang dapat mengidentifikasi hubungan kesamaan antar item. Algoritme apriori dapat digunakan untuk membentuk kandidat kombinasi item untuk diterapkan aturan asosiatifnya yang mempunyai nilai keseringan tertentu. Algoritme ini telah diterapkan dalam beragam aplikasi di [1], [2], [5]-[14]. Pentingnya aturan asosiasi dapat diketahui dari dua parameter, yaitu minimum support (persentase kombinasi item dari seluruh transaksi) dan minimum confidence (kuatnya hubungan antar item dalam aturan asosiatif) .

Berbeda dengan penerapan algoritme apriori dalam sistem di atas, penelitian ini bertujuan mengkaji penerapan algoritme dan association rule ini pada dataset transaksi pembelian untuk memberikan rekomendasi produk promosi bagi pelanggan. Penerapan ini dilakukan di PT. Agro Express Indonesia yang berdiri pada awal tahun 2018 dan menjual beraneka macam buah-buahan segar. Dataset berupa data transaksi penjualan bulan Oktober dan November 2018. Analisis pola frekuensi tertinggi menghasilkan kombinasi item yang memenuhi syarat minimum support yang sudah ditentukan. Pembentukan pola association rule dilakukan untuk menemukan aturan asosiasi yang memenuhi minimum confidence dari frekuensi tinggi yang telah ditemukan.

\section{Metode Penelitian}

Penelitian ini menerapkan algoritma apriori pada dataset berupa data histori transaksi. Tahapan-tahapan penelitian adalah pengumpulan data, prapemrosesan data, analisis pola frekuensi tertinggi menggunakan algoritme apriori, pembentukan pola association rule, dan pengujian hasil eksperimen. Penerapan association rule dengan algoritme apriori mempunyai kelebihan pada kesederhanaan dan kemampuan menangani data besar sehingga lebih mudah digunakan secara praktis oleh perusahaan dengan kemampuan pengolahan data yang terbatas. Penelitian ini menggunakan aplikasi Weka 3.9.

\section{A. Pengumpulan Data}

Pada tahap pengumpulan data, dilakukan survei lapangan dengan melakukan wawancara. Dari hasil wawancara yang dilakukan, diketahui bahwa perusahaan tidak mengolah data yang dimiliki dan tidak mempunyai acuan dalam melakukan promosi produk. Data penjualan digunakan untuk rekomendasi produk, yaitu data transaksi penjualan sebanyak 1.027 transaksi selama dua bulan yaitu bulan Oktober dan November 2018.

\section{B. Prapemrosesan Data}

Tahap prapemrosesan mempersiapkan data yang diperoleh dari tahap pengumpulan data sehingga format maupun substansinya sesuai dengan kebutuhan eksperimen. Jumlah data yang sebelumnya terdapat 1027 data, setelah dilakukan prapemrosesan menjadi
Tabel 1. Pemilihan atribut

\begin{tabular}{cccc}
\hline Atribut & $\begin{array}{c}\text { Detail } \\
\text { Penggunaan }\end{array}$ & Atribut & $\begin{array}{c}\text { Detail } \\
\text { Penggunaan }\end{array}$ \\
\hline Invoice & $\checkmark$ & Qty & $\mathrm{X}$ \\
Nama & $\mathrm{x}$ & Satuan & $\mathrm{X}$ \\
Pelanggan & & Harga & $\mathrm{x}$ \\
Telefon & $\mathrm{X}$ & Basket Size & $\mathrm{x}$ \\
Platform & $\mathrm{x}$ & Alasan & $\mathrm{x}$ \\
Nama & $\checkmark$ & Discount & \\
Produk & & & \\
\hline
\end{tabular}

menjadi 468 instan. Setiap instan data terdiri dari 30 atribut. Atribut pertama merupakan no.order dan 29 atribut yang lain adalah item produk. Hasil akhirnya adalah representasi data berupa vektorisasi data matriks biner berukuran 468 baris x 30 kolom. Matrik vektorisasi data ini dibuat untuk menyesuaikan format representasi data sehingga sesuai dengan format masukan data algoritma apriori pada aplikasi Weka. Konversi data dilakukan dari data mentah menjadi data yang dapat diproses yaitu .csv atau .arff.

Tahap prapemrosesan ini meliputi ekstraksi data, data cleaning, dan konversi data. Ekstraksi data dilakukan karena tidak semua atribut data awal diperlukan. Dari semua atribut, hanya informasi no. invoice dan produk penjualan yang digunakan (dengan tanda $\checkmark$ ), sedangkan atribut yang lain seperti nama pelanggan, no. telepon, quantity, dan platform diabaikan. Tabel 1 menyajikan pemetaan penggunaan dari atribut data asal pada penelitian ini.

Pembersihan data dilakukan untuk menghilangkan data yang ambigu, menghilangkan instan data yang tidak digunakan dan membuang atribut yang tidak diperlukan. Contoh data yang tidak digunakan adalah no.invoice dengan pembelian 1 varian produk, penjualan produk selain buah, dan paket healthy product. Contoh data ambigu adalah data yang hanya berisi no.invoice tanpa ada transaksi. Pembersihan data juga diterapkan untuk keperluan penyeragaman ejaan dan menghilangkan data transaksi berisi produk yang tidak digunakan seperti parcel, pita, plastik, dan produk lain selain buah.

Setelah data dibersihkan sesuai keperluan, dilakukan konversi representasi data sehingga sesuai dengan spesifikasi format data untuk Weka 3.9. Respresentasi data hasil pembersihan dan konversi data disajikan dalam Tabel 2. No. invoice seperti 6423, 6429, 6430, 6434, dan 6435 merupakan ID transaksi penjualan. Almond, alpukat, anggur, apel, asam bangkok, dan avomango merupakan item produk yang dijual pada perusahaan. Nilai Y merupakan produk yang dibeli oleh pelanggan. Nilai $\mathrm{N}$ merupakan produk yang tidak dibeli oleh pelanggan.

\section{Analisis Pola Frekuensi Tinggi}

Pada tahap analisis pola frekuensi tinggi ditentukan kombinasi item yang memenuhi syarat minimum dari nilai support pada seluruh transaksi. Untuk keperluan 
Tabel 2. Hasil konversi transaksi penjualan

\begin{tabular}{cccccc}
\hline $\begin{array}{c}\text { No. } \\
\text { invoice }\end{array}$ & Almond & Alpukat & Anggur & $\ldots$ & $\begin{array}{c}\text { Salak } \\
\text { Pondoh }\end{array}$ \\
\hline 6423 & $\mathrm{~N}$ & $\mathrm{~N}$ & $\mathrm{Y}$ & $\ldots$ & $\mathrm{N}$ \\
6429 & $\mathrm{~N}$ & $\mathrm{~N}$ & $\mathrm{Y}$ & $\ldots$ & $\mathrm{N}$ \\
6230 & $\mathrm{Y}$ & $\mathrm{N}$ & $\mathrm{N}$ & $\ldots$ & $\mathrm{N}$ \\
6234 & $\mathrm{Y}$ & $\mathrm{N}$ & $\mathrm{N}$ & $\ldots$ & $\mathrm{N}$ \\
6435 & $\mathrm{Y}$ & $\mathrm{N}$ & $\mathrm{Y}$ & $\ldots$ & $\mathrm{N}$ \\
$\ldots$. & $\ldots$ & $\ldots$ & $\ldots$ & $\ldots$ & $\ldots$ \\
7493 & $\mathrm{~N}$ & $\mathrm{Y}$ & $\mathrm{N}$ & $\ldots$ & $\mathrm{N}$ \\
\hline
\end{tabular}

tersebut dilakukan pembentukan model mining menggunakan algoritme apriori untuk mencari kombinasi itemset yang mempunyai nilai keseringan tertentu. Nilai support ditentukan sesuai Persamaan 1a. Nilai support untuk dua item digunakan Persamaan $1 \mathrm{~b}$. Parameter $T_{A}$ menyatakan jumlah transaksi yang mengandung $A, T_{A \cap B}$ transaksi yang mengandung $A$ dan B, $T_{A \cap B \cap C}$ transaksi yang mengandung $A, B$ dan C, dan $T_{\text {total }}$ jumlah transaksi total.

$$
\begin{aligned}
\operatorname{Support}(A) & =\frac{T_{A}}{T_{\text {total }}} \\
\operatorname{Support}(A, B) & =\frac{T_{A \cap B}}{T_{\text {total }}} \\
\operatorname{Support}(A, B, C) & =\frac{T_{A \cap B \cap C}}{T_{\text {total }}}
\end{aligned}
$$

\section{Pembentukan Association Rule}

Setelah frekuensi tinggi diperoleh, aturan yang memenuhi syarat confidence minimum dicari dengan menghitung confidence aturan asosiatif. Dalam menghitung confidence dilakukan pertukaran itemset. Misalkan kombinasi 2 itemset yaitu $\mathrm{A} \rightarrow \mathrm{B}$, maka dibalik menjadi $\mathrm{B} \rightarrow \mathrm{A}$. Begitu juga dengan kombinasi 3 itemset yaitu $\mathrm{A}, \mathrm{B} \rightarrow \mathrm{C}$, maka dibalik menjadi $\mathrm{A}, \mathrm{C}$ $\rightarrow \mathrm{B}$ dan B, C $\rightarrow$ A. Masing-masing nilai support itemset mungkin akan tetap sama, namun kemungkinan akan mempunyai nilai confidence yang berbeda. Hal ini untuk mengetahui nilai confidence mana yang terbesar dari setiap itemset. Perhitungan confidence untuk kombinasi 2 itemset dinyatakan dalam Persamaan 2a. Perhitungan confidence untuk kombinasi 3 itemset dinyatakan dalam Persamaan 2b.

$$
\begin{gathered}
\text { Confident }(A, B)=\frac{T_{A \cap B}}{T_{A}} \\
\text { Confident }(A, B, C)=\frac{T_{A \cap B \cap C}}{T_{A \cap B}}
\end{gathered}
$$

\section{E. Uji Lift Ratio Pada Aturan}

Tahapan uji lift ratio menghasilkan ukuran untuk menguji kevalidan aturan yang sudah terbentuk dan mengetahui kekuatan pada association rule yang telah terbentuk. Pada tahap ini dilakukan pengajian kevalidan aturan apakah benar produk A dibeli bersamaan dengan produk B. Suatu aturan dikatakan valid jika nilai lift ratio lebih dari 1 . Hal ini berarti aturan dapat digunakan sebagai acuan dalam rekomendasi produk. Nilai lift ratio dihitung dengan menggunakan Persamaan 3. Nilai benchmark confidence diperoleh dengan menggunakan Persamaan 4. Parameter $B C(A, B)$ menyatakan benchmark confidence produk A dan B. Parameter $N_{c}$ menyatakan jumlah transaksi dengan item yang menjadi consequent, sedangkan $N$ jumlah transaksi keseluruhan.

$$
\begin{aligned}
& \text { Lift Ratio }(A, B)=\frac{\text { Confident }(A, B)}{B C(A, B)} \\
& B C(A, B)=\frac{N_{C}}{N}
\end{aligned}
$$

\section{III.HASIL DAN PEMBAHASAN}

Penelitian ini dilakukan 3 tahapan utama yaitu melakukan analisa pola frekuensi tinggi menggunakan algoritma apriori, pembentukan aturan asosiasi, dan uji kekuatan aturan yang terbentuk dengan menghitung lift ratio. Hasil akhir penelitian ini berupa aturan asosiasi yang dijadikan sebagai acuan dalam promosi produk perusahaan dan pendukung keputusan dalam memberikan rekomendasi produk kepada konsumen.

Tabel 3 menunjukkan pembentukan 1 itemset dengan nilai frekuensi pembelian dan support-nya. Nilai support diperoleh dengan Persamaan 1a. Dari itemset tersebut dibentuk 1 itemset yang memenuhi syarat minimum support (minsup) 85\% yang ditunjukkan dalam Tabel 4. Pemfilteran memperoleh 1 itemset sejumlah 6 macam buah-buahan. Proses pembentukan 2 itemset yang memenuhi syarat minimum support 85\% ditunjukkan pada Tabel 5. Nilai support diperoleh dengan menggunakan Persamaan $1 \mathrm{~b}$.

Pembentukan 3 itemset hanya menghasilkan \{GrapeOla, Jeruk, Pear\} yang memenuhi syarat minimum support 85\%. Nilai support diperoleh dengan menggunakan Persamaan 1c. Proses penghitungan support dan pembentukan itemset dihentikan saat 3 itemset tidak bisa dikombinasikan kembali. Pembentukan aturan asosiasi dibentuk dari kombinasi yang memenuhi minimum support. Tabel 6 menunjukkan aturan asosiasi yang dibentuk dari pola kombinasi 2 itemset. Pembentukan asosiasi dari pola kombinasi 3 itemset menghasilkan aturan yang ditunjukkan dalam Tabel 7.

Dua aturan terbaik yang mempunyai nilai confidence tertinggi yaitu $100 \%$ ditunjukkan dalam Tabel 8. Aturan yang terbentuk memudahkan perusahaan dalam mengambil kesimpulan seperti halnya dalam [1], [2], [5]-[14]. Kajian ini menghasilkan hanya dua aturan terbaik berdasarkan pemenuhan minimum support dan nilai confidence, tidak seperti dalam [8] 
Tabel 3. Pembentukan 1 itemset

\begin{tabular}{|c|c|c|}
\hline Nama & Frekuensi & Support (\%) \\
\hline Almond & 137 & 29,27 \\
\hline Alpukat & 247 & 52,78 \\
\hline Anggur & 211 & 45,09 \\
\hline Apel & 313 & 66,88 \\
\hline Asam Bangkok & 398 & 85,04 \\
\hline Avomango & 108 & 23,08 \\
\hline Blueberry Argentina & 406 & 86,75 \\
\hline Buah Naga & 225 & 48,08 \\
\hline Buah Tin & 160 & 34,19 \\
\hline Cherry Australia & 236 & 50,43 \\
\hline Chia Seed & 389 & 83,12 \\
\hline Delima & 250 & 53,42 \\
\hline Durian Monthong Frozen & 201 & 42,95 \\
\hline GrapeOla & 404 & 86,32 \\
\hline Jambu Kristal & 203 & 43,38 \\
\hline Jeruk & 426 & 91,03 \\
\hline Kiwi & 276 & 58,97 \\
\hline Kurma & 225 & 48,08 \\
\hline Lemon & 300 & 64,10 \\
\hline Lengkeng Bangkok & 246 & 52,56 \\
\hline Mangga & 423 & 90,38 \\
\hline Melon Golden & 266 & 56,84 \\
\hline Nanas Honi & 201 & 42,95 \\
\hline Nectarin Australia & 188 & 40,17 \\
\hline Peach Australia & 203 & 43,38 \\
\hline Pear & 426 & 91,03 \\
\hline Pisang Cavendish & 221 & 47,22 \\
\hline Plum & 54 & 11,54 \\
\hline Salak Pondoh & 20 & 4,27 \\
\hline
\end{tabular}

yang menghasilkan terlalu banyak aturan sehingga menyulitkan dalam pengambilan keputusan.

Selain itu, diperoleh lift ratio dengan nilai $>1$. Hal ini berarti bahwa tingkat kevalidan aturan dapat digunakan sebagai acuan dalam rekomendasi produk. Pada penelitian sebelumnya tingkat kevalidan aturan jarang digunakan sebagai penunjang keakuratan hasil penelitian, seperti pada penelitian [14]. Hasil analisa menunjukkan bahwa aturan dengan akurasi tertinggi dan lift ratio 1,10 adalah bahwa benar produk Jeruk dibeli bersama dengan Pear dengan nilai lift ratio sebesar 1,10 dan benar produk GrapeOla dan Jeruk dibeli bersama dengan Pear dengan nilai lift ratio sebesar 1,10.

Dari hasil eksperimen dengan aplikasi Weka dengan nilai minimum support $85 \%$ dan nilai confidence sebesar 90\%, menunjukkan hasil yang sama dengan perhitungan manual. Hasil pengujian yang dilakukan pada aplikasi weka 3.9 seperti Gambar 1. Ditemukan 10 aturan pola pembelian yang sesuai dengan kriteria yang diinginkan. Dari 10 aturan terbaik di atas, diambil aturan yang mempunyai nilai confidence dan lift ratio tertinggi yang menghasilkan 2 aturan terbaik. Jika pelanggan membeli Jeruk (426 kemungkinan), maka pelanggan juga membeli Pear (426 kemungkinan) dengan akurasi nilai confidence $100 \%$ dan lift ratio 1,1. Jika pelanggan membeli GrapeOla dan Jeruk (400 kemungkinan), maka pelanggan juga membeli Pear (400
Tabel 4. Hasil filter 1 itemset dengan minsup 85\%

\begin{tabular}{lcc}
\hline \multicolumn{1}{c}{ Detail Penjualan } & Frekuensi & Support (\%) \\
\hline Asam Bangkok & 398 & 85,04 \\
Blueberry Argentina & 406 & 86,75 \\
GrapeOla & 404 & 86,32 \\
Jeruk & 426 & 91,03 \\
Mangga & 423 & 90,38 \\
Pear & 426 & 91,03 \\
\hline
\end{tabular}

Tabel 5. Kombinasi 2 itemset dengan minsup 85\%

\begin{tabular}{lcc}
\hline \multicolumn{1}{c}{ Detail Penjualan } & Frekuensi & Support (\%) \\
\hline GrapeOla, Jeruk & 400 & 85,47 \\
GrapeOla, Pear & 400 & 85,47 \\
Jeruk, Pear & 426 & 91,03 \\
\hline
\end{tabular}

Tabel 6. Aturan hasil dari kombinasi 2 itemset

\begin{tabular}{lcc}
\hline \multicolumn{1}{c}{ Rule } & Frekuensi & Confidence (\%) \\
\hline $\begin{array}{l}\text { Jika GrapeOla terjual, } \\
\text { maka Jeruk terjual }\end{array}$ & 400 & 99,01 \\
$\begin{array}{l}\text { Jika Jeruk terjual, maka } \\
\text { GrapeOla terjual }\end{array}$ & 400 & 93,90 \\
$\begin{array}{l}\text { Jika GrapeOla terjual, } \\
\text { maka Pear terjual }\end{array}$ & 400 & 99,01 \\
$\begin{array}{l}\text { Jika Pear terjual terjual, } \\
\text { maka GrapeOla terjual }\end{array}$ & 400 & 93,90 \\
$\begin{array}{l}\text { Jika Jeruk terjual, maka } \\
\begin{array}{l}\text { Pear terjual } \\
\text { Jika Pear terjual terjual, } \\
\text { maka Jeruk terjual }\end{array}\end{array}$ & 426 & 100 \\
\hline
\end{tabular}

Tabel 7. Aturan hasil dari kombinasi 3 itemset

\begin{tabular}{lcc}
\hline \multicolumn{1}{c}{ Rule } & Frekuensi & $\begin{array}{c}\text { Confidence } \\
\text { (\%) }\end{array}$ \\
\hline $\begin{array}{l}\text { Jika Grapeola dan Jeruk } \\
\text { terjual, maka Pear terjual }\end{array}$ & 400 & 100 \\
$\begin{array}{l}\text { Jika Grapeoladan Pear } \\
\text { terjual, maka Jeruk terjual } \\
\text { Jika Jeruk dan Pear terjual, } \\
\text { maka GrapeOla terjual }\end{array}$ & 400 & 100 \\
\hline
\end{tabular}

Tabel 8. Aturan terbaik yang dihasilkan dan lift rationya

\begin{tabular}{lccc}
\hline \multicolumn{1}{c}{ Detail Penjualan } & $\begin{array}{c}\text { Support } \\
(\mathbf{\%})\end{array}$ & $\begin{array}{c}\text { Confidence } \\
\text { (\%) }\end{array}$ & $\begin{array}{c}\text { Lift } \\
\text { Ratio }\end{array}$ \\
\hline $\begin{array}{l}\text { Jika Jeruk terjual, } \\
\text { maka Pear terjual }\end{array}$ & 91,03 & 100 & 1,1 \\
$\begin{array}{l}\text { Jika GrapeOla dan } \\
\text { Jeruk terjual, maka } \\
\text { Pear terjual }\end{array}$ & 85,47 & 100 & 1,1 \\
\hline
\end{tabular}

kemungkinan) dengan akurasi nilai confidence $100 \%$ dan lift ratio 1,1 . 


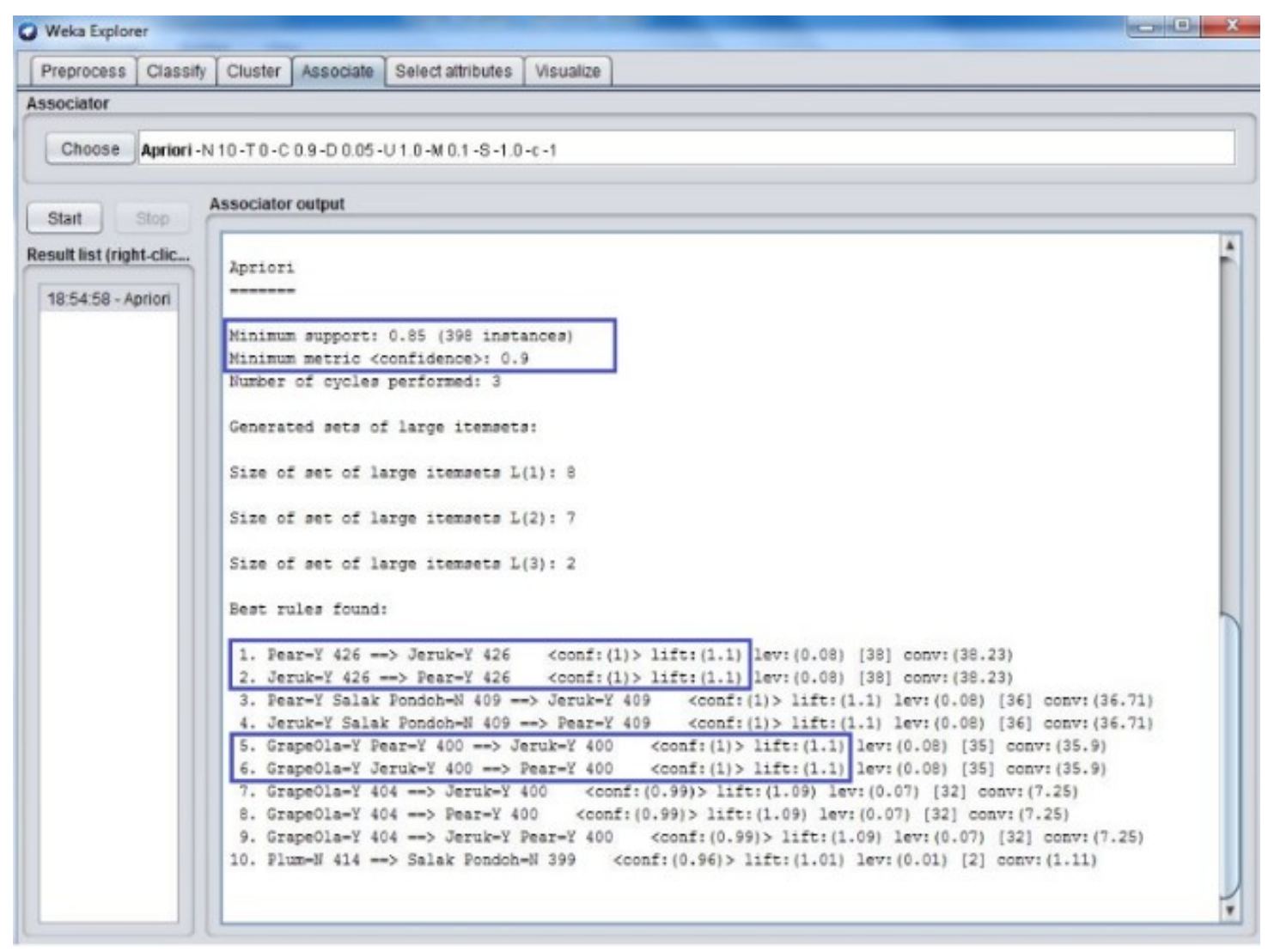

Gambar 1. Hasil eksperimen menggunakan Weka 3.9

Beberapa aturan yang terbentuk di atas dapat digunakan sebagai acuan dalam rekomendasi produk seperti halnya dalam [5], [9], [12], dan [14]. Strategi pemasaran dapat dilakukan, misalnya bundling product (grapeola, jeruk, dan pear akan dijual menjadi satu paket hemat), buy 2 get 1 (jika membeli 2 kg jeruk akan mendapat $1 \mathrm{~kg}$ pear), dan diskon produk (mendapat diskon 5\% jika membeli Jeruk di atas $5 \mathrm{~kg}$ ). Dengan demikian, perusahaan mempunyai acuan untuk menangani strategi pemasaran, tidak hanya perkiraan saja. Hasil penelitian ini dapat diimplementasikan perusahaan untuk mendukung strategi pemasaran. Usaha perbaikan hasil juga masih bisa ditingkatkan misalnya dengan melakukan modifikasi nilai support dan confidence minimum untuk memperoleh yang lebih baik atau penerapan algoritma asosiasi lain, seperti algoritme FP-Growth [15], Generalized Rules Induction, atau algoritma hash-based.

\section{KESIMPULAN}

Algoritma apriori yang diujicobakan pada dataset transaksi penjualan fleksibel untuk digunakan sebagai dasar pengambilan keputusan perusahaan pada area pemasaran. Aturan asosiasi yang terbentuk dapat digunakan sebagai acuan untuk rekomendasi produk yang memenuhi nilai confidence dan support minimum.

\section{UCAPAN TERIMA KASIH}

Penulis menyampaikan terima kasih kepada PT. Agro Express Indonesia atas partisipasinya untuk memberikan data transaksi penjualan dalam pelaksanaan penelitian.

\section{DAFTAR PUSTAKa}

[1] S. D. Cahyo, "Sistem Rekomendasi Pembuatan Paket Menu dengan Market Basket Analysis Menggunakan Algoritma Apriori pada Rumah Makan Kampung Laut Semarang,” B. Thesis, Universitas Dian Nuswantoro, Semarang, Indonesia, 2017. [Online]

[2] F. Fitriyani, "Implementasi Algoritma Fp- Growth Menggunakan Association Rule Pada Market Basket Analysis,” Jurnal Informatika, vol. 2, no. 1, pp. 296-305, 2015.

[3] M. I. Ghozali, R. Z. Ehwan, and W. H. Sugiharto, “Analisa Pola Belanja Menggunakan Algoritma Fp Growth, Self Organizing Map (SOM) dan K Medoids," Simetris: Jurnal Teknik Industri, Mesin, Elektro dan Ilmu Komputer, vol. 8, no. 1, pp. 317-326, 2017.

[4] G. I. Marthasari, Y. Azhar, and D. K. Puspitaningrum, "Sistem Rekomendasi Penyewaan Perlengkapan Pesta Menggunakan Collaborative Filtering dan Penggalian Aturan Asosiasi,” Jurnal Simantec, vol. 5, no. 1, pp. 1-8, 2015. 
[5] S. Widjaya, "Sistem Penunjang Keputusan untuk Menentukan Barang Terlaris dengan Algoritma Apriori pada CV Calosa Global Indonesia,” JIntech: Journal of Information and Technology, vol. 5, no. 2, pp. 139-146, 2017.

[6] R. Buaton, Y. Maulita, and A. Kristiawan, "Korelasi Faktor Penyebab Tindak Kekerasan dalam Rumah Tangga Menggunakan Data Mining Algoritma A Priori,” Jurnal Media Infotama, vol. 14, no. 1, pp. 21-30, 2018.

[7] F. Indriani, "Pola Asosiasi Bahan pada Resep Masakan Daerah dengan Algoritma Apriori," SISFOTEK, vol. 1, no. 1, pp. 119-123, 2017.

[8] W. Aprianti, K. A. Hafizd, and M. R. Rizani, "Implementasi Association Rules dengan Algoritma Apriori pada Dataset Kemiskinan," Limits: Journal of Mathematics and Its Applications, vol. 14, no. 2, pp. 145-155, 2017.

[9] H. D. Hutahaean, B. Sinaga, and A. A. Rajagukguk, “Analisa Dan Perancangan Aplikasi Algoritma Apriori Untuk Korelasi Penjualan Produk (Studi Kasus: Apotik Diory Farma)," Journal of Informatics Pelita Nusantara, vol. 1, no. 1, pp. 7-13, 2016.

[10] R. I. E. Saragih and H. Sembiring, "Penerapan Algoritma Apriori Data Mining Untuk Mengetahui Kecurangan Skripsi," Majalah Ilmiah Methoda, vol. 5, no. 2, pp. 1-7, 2015.
[11] M. Fauzy, K. R. Saleh, and I. Asror, "Penerapan Metode Association Rule Menggunakan Algoritma Apriori Pada Simulasi Prediksi Hujan Wilayah Kota Bandung,” Jurnal Ilmiah Teknologi Informasi Terapan, vol. 13, no. 2, pp. 221-227, 2016.

[12] A. Ikhwan, Sriani, and D. Nofriansyah, "Penerapan Algoritma Apriori Untuk Menganalisa Transaksi Penjualan Untuk Promo Produk Furniture Jepara," in Konferensi Nasional Pengembangan Teknologi Informasi dan Komunikasi, Medan, Indonesia, 2015, pp. 19-24.

[13] G. A. Syaripudin and E. Faizal, "Implementasi Algoritma Apriori Dalam Menentukan Persediaan Obat,” JIKO (Jurnal Inform. dan Komputer), vol. 2, no. 1, pp. 10-14, 2017.

[14] I. Djamaludin, “Analisis Pola Pembelian Konsumen pada Transaksi Penjualan Menggunakan Algoritma Apriori," Simetris: Jurnal Teknik Mesin, Elektro dan Ilmu Komputer, vol. 8, no. 2, pp. 671-678, 2017.

[15] R. Fitria, W. Nengsih, and D. H. Qudsi, "Implementasi Algoritma Fp-Growth Dalam Penentuan Pola Hubungan Kecelakaan Lalu Lintas,” Jurnal Sistem Informasi, vol. 13, no. 2, pp. 11-20, 2017. 